\title{
La Influencia de la Interdisciplinariedad en el Razonamiento Jurídico de los Jueces y Abogados
}

The Influence of Interdisciplinarity in the Juridical Reasoning of Judges and Lawyers

Gabriela Estefanía Coronel Loayza

Investigadora Jurídica, Estudio Vaca \& Asociados

Mgtr. Jessahé Carla Navarrete Villalba

Docente titular PUCE (Facultad de Jurisprudencia)

Artículo Original (Revisión)

RFJ, No. 3, 2018, pp. 61-80, ISSN 2588-0837

RESUMEN: el documento considera a la educación como la base del desarrollo de la sociedad. En ese sentido, discute la necesidad de cambiar la enseñanza tradicional de la disciplina jurídica (basada en un enfoque positivista) enfocada en escenarios de conflicto. Con este objetivo se propone profundizar en el estudio interdisciplinar del Derecho con el objetivo de alcanzar un cambio de rumbo.

PALABRAS CLAVES: Derecho, educación legal, interdisciplinariedad, derecho de conceptos, globalización.

ABSTRACT: this paper discuss education as the basis for the development of society. In this regard, it examines the need to change the traditional teaching of Law (positivist approach) which is focused on conflict scenarios. With this target is proposed to deep in the interdisciplinary study of Law for achieving a real change.

KEY WORDS: Law, legal education, interdisciplinarity, right of concepts, globalization. 


\section{INTRODUCCIÓN}

El Derecho regula las distintas relaciones interpersonales y los conflictos de diversa índole que se generan dentro de la sociedad en diferentes ámbitos. "El Derecho ha adquirido un nuevo lugar social y ha generado expectativas sociales nuevas respecto de su función de regulación de las relaciones sociales". (Ansolabehere, 2008, 332). Los jueces y los abogados que tienen como función principal la aplicación del Derecho, no pueden apartarse de la realidad y deben tener un conocimiento amplio y especializado sobre cada disciplina o ciencia en la que se encuentre inmerso el conflicto.

La necesidad de jueces se siente paradójicamente más a medida que se extiende la costumbre de aceptar que cada cual haga lo que quiera. Siempre que no se perjudique al otro". (Gomis, 2002, 3). Es necesario proyectar una administración de justicia más eficiente y justa gracias al razonamiento jurídico interdisciplinario del abogado y el juez.

Se debe analizar la influencia de la interdisciplinariedad de las diversas ramas del Derecho en el razonamiento que interviene en la decisión del juez al momento de generar por consiguiente, sentencias más íntegras y justas que ponen fin a cada uno de los casos de su jurisdicción. Para esto, es necesario identificar el modelo de enseñanza tradicional - positivista que domina la malla curricular en las facultades de Jurisprudencia latinoamericanas, para advertir la imperiosa necesidad de un cambio en el modelo educativo.

Al relacionar al Derecho con el fenómeno de la globalización se producirá un cambio en el rol que desempeñan el abogado y el juez, este rol presenta una visión más amplia y significativa, además, trasciende más allá del simple papel de agentes en la solución de conflictos.

La globalización trae consigo cambios tecnológicos importantes, que están generando una revolución en todas las áreas e industrias. El Derecho no es la excepción, por lo cual debemos preguntarnos: ¿Qué estamos haciendo en las Facultades de Derecho para adaptarnos a estos cambios?

1 Ansolabehere, K. (2008). Legalistas, legalistas moderados y garantistas moderados: Ideología legal de maestros, jueces, abogados, ministerios públicos y diputados. Revista Mexicana de Sociología, 70(2), 331-359.

2 Gomis, L. (2002). No hay justicia sin jueces. El Ciervo,39(475/476), 3-3. 
Debemos repasar la historia de la humanidad para recordar que el Derecho requiere de cambios a medida que la sociedad se transforma. Por ejemplo, cuando ocurrió el cambio de procesos productivos de manuales a industriales la normativa laboral tuvo un cambio radical, creando por primera vez la protección de los derechos a los trabajadores.

Actualmente, los procesos judiciales cada vez más se convierten en la última opción de los actores y demandados. "Hoy en día se requiere un juez que sepa diferenciar cuándo existen controversias y cuándo no las hay para, en el segundo de los casos, impulsar mecanismos conciliatorios donde sean las propias partes involucradas las que encuentren la solución a su conflicto y, en el primero de los casos, allí donde existan posiciones encontradas e irreconciliables, buscar la solución que mejor satisfaga la paz y la convivencia social. La construcción de una justicia restaurativa es el desafío en este siglo y el juez debe asumir el rol protagónico que le corresponde en esa construcción”. (Muñoz, 2013, 3)

La única forma que el juez desarrolle y cumpla con las capacidades que la ciudadanía espera de él, gestione la conflictividad y contribuya a una sociedad más pacífica e igualitaria, es conociendo la comunidad en que vive, conociendo sus conflictos, su cultura, sus por menores. Un juez que se aparta o rechaza a la sociedad sobre la que luego ejercerá un poder inmenso, no es otra cosa que un mal juez. No puede juzgarse sobre realidades que no se conocen.

Frente al fenómeno de la globalización, el jurista debe desarrollarse a la par con las diversas interacciones y fenómenos sociales, no debe desatender la realidad, debe dominar conceptos e ideas nucleares que se encuentren fuera de la ciencia jurídica. El estudio del Derecho cada vez más exige que el conocimiento adquirido al momento de salir de la Universidad sea interdisciplinario.

La función del juez es indispensable en una sociedad, el juez tiene como función principal la de administrar justicia, a través de las sentencias que ponen fin a un conflicto y esta sentencia se ve influenciada por el razonamiento jurídico. Es fundamental que el conocimiento sea más allá del tecnicismo jurídico, porque el Juez debe conocer realidades diversas, entornos sociales que trasciendan más allá del ámbito legal, debe tener un dominio importante sobre el razonamiento jurídico del administrador y ejecutor de justicia.

3 Muñoz, C. (2013). El oficio de ser Juez. Revista de Derecho UNAM, 5, 2-8. 


\section{EL DERECHO DE CONCEPTOS}

\section{a. Enfoque tradicional positivista del Derecho}

A lo largo de la historia, el ejercicio y enseñanza del Derecho se ha centrado en la abstracción de conceptos como la justicia, equidad, ley, etc. Las normas son el eje principal del proceso de aprendizaje, el papel del profesor ha sido relegado a ser un transmisor de conocimientos, lo que tiene como consecuencia que los estudiantes no poseen un espíritu investigador e innovador. La enseñanda tradicional ha brindado menor importancia al objetivo principal y el fin del Derecho: regular las relaciones sociales y la obtención del bien común.

El enfoque positivista señala que el Derecho es un conjunto de normas generales emanadas de un órgano legislativo, que deben ser cumplidas, caso contrario existirá una sanción. Rachel Hernández, tratadista del Derecho, manifiesta que: "asumir actualmente una posición positivista es subordinarnos ciegamente a la ley como herramienta ajena a principios y valores, y, por ende, de espaldas a la moral media de la sociedad y a los intereses emanados del pueblo, es hacer honor a la voluntad estatal sin importar su apego a las necesidades de la sociedad". ${ }^{4}$

Desde un punto de vista histórico, el Derecho ha sido interpretado, estudiado y analizado desde una perspectiva principalmente positivista. Según Beade: "tradicionalmente, algunos teóricos defienden la idea que el Derecho tiene una sola estructura que permite pensar (y resolver correctamente) los diferentes casos que se presentan ante jueces y tribunales. Según estos teóricos, el Derecho es uno solo y no puede, ni debe, estar abierto a resolver cuestiones que alteren su homogeneidad". ${ }^{5}$ El estudio del Derecho en Universidades Latinoamericanas se ha sustentado exclusivamente en un enfoque tradicional-positivista, basado en los conceptos y en una visión coercitiva.

Con la realidad que vive la humanidad, es absurdo dar la espalda a la manera en la que la sociedad se desenvuelve y su constante y rápida transformación, para centrarnos en las normas como la única forma

4 Hernández, R. (2017). La crisis del positivismo jurídico. Revista jurídica Ámbito Jurídico, (2), 1-11.

5 Beade, G.A. (2015). Los problemas del unitarismo del derecho. Revista Jurídica Universidad de Palermo,221-222. 
de resolución de conflictos. Si la sociedad ha evolucionado, el Derecho debería hacerlo también de un sistema de control coactivo y coercitivo a un sentido más amplio que comprende la integración de las diversas ciencias de manera integradora y transversal.

\section{b. La relación del derecho con la coacción}

La enseñanza legal ha sido marcada por la idea de la relación entre Derecho y la coacción. Todo elemento jurídico lleva implícito la capacidad del uso de la fuerza para el cumplimiento de la norma, esta característica es precisamente lo que diferencia a la norma jurídica de las normas morales y religiosas. "la coacción tiene una función tácita que expresa una relación de dominación.”' (Tiznado, 2011, 81). El Estado será el encargado de hacer cumplir dichas normas jurídicas mediante la coacción. "La actividad del Estado consiste en deliberaciones cuyo objeto final es producir pensamientos aptos para dirigir la conducta colectiva; la aplicación y la ejecución de tales pensamientos es la función que compete a los diferentes sectores de la administración".’ (Zúñiga, 1973, 119).

La coacción ha sido aceptada como la presión colectiva que ejerce la comunidad a través del Estado, para que un individuo cumpla las disposiciones legales. A través de la coacción, el Estado puede ejercer fuerza legítima con sus jueces para el cumplimiento de la ley.

El principal problema es que esta concepción genera una estructura de conflicto y confrontación; por esta razón en las facultades de Jurisprudencia de las diversas universidades, se da más prioridad a que los estudiantes aprendan a pelear (litigio) que a la búsqueda de una solución distinta que involucre el conocimiento en el área de otra ciencia. "Los objetivos fundacionales de la Justicia no parece que fueran castigar ni practicar la venganza, sus objetivos son, con certeza, mucho más inteligentes: se trata de reformar los comportamientos asociales, devolver a la víctima y al agresor la dignidad perdida y posibilitar, de nuevo,

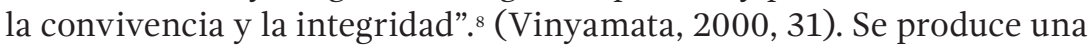

6 Tiznado, J. (2011). Tolerancia, autonomía e inmoralidades "inofensivas" o "sin víctimas" Crítica: Revista Hispanoamericana De Filosofía, 43(128), 81-86.

7 Zúñiga, L. (1973). Durkheim: Su concepción del Estado y la Primera Guerra Mundial. Revista Española de la Opinión Pública, (32), 119-153.

8 Vinyamata, E. (2000). La Resolución de Conflictos, una nueva disciplina. El Ciervo, 48(578), 31-33. 
contradicción con el fin de la Justicia y el modelo de enseñanza legal que se encuentra basado en el conflicto desde una perspectiva errónea. El conflicto solo se puede entender si se plantea como un fenómeno universal que traspasa denominaciones, ámbitos y niveles.

Esta postura en la práctica está disminuyendo significativamente, porque con cada vez más frecuencia aparece el auge de centros de mediación alternativos a la solución de conflictos. Y esta realidad no es solo ecuatoriana, sino latinoamericana.

\section{EL DERECHO Y LA GLOBALIZACIÓN}

Se empezará definiendo a la globalización y la relación que el Derecho mantiene con ella. La globalización es un fenómeno palpable, sobre todo, a partir de finales del siglo XX y comienzos del siglo XXI. Según Martínez "es un fenómeno que interpela a las más diversas disciplinas sociales y que ha suscitado los más variados enfoques y perspectivas"

Alegría, en su obra Derecho y Globalización señala que: "no cabe duda que la globalización, de la que se discute su verdadero origen en el tiempo, tiene ya muchas facetas: la llamada "aldea global" de la información, sus costados económicos, sus aspectos culturales, las repercusiones políticas en las decisiones de los Estados y en aquellas que se les imponen o se les hacen imperiosas por influencias externas; $y$, en definitiva, como ha expresado Joseph Stiglitz, el "rostro humano", o sea, las implicancias sobre la realización de los individuos en la comunidad local y universal"10

Se manifiesta a grandes rasgos como la experiencia cultural de un mundo sin límites, en el que las fronteras se eliminan. "Aunque desiguales, los efectos de la globalización son sin duda inevitables, y están estrechamente vinculados a la extensión, la aceleración y la radicalización de dinámicas que conducen a la planetarización de variados procesos sociales". ${ }^{11}$ (Martínez, 2003, 170)

9 De la Peña Martínez, F. (2003). Antropología del presente y globalización. Boletín De Antropología Americana, (39), 175-183.

10 Alegria, H. (2017). Derecho y Globalización. Revista Jurídica uba.187.

11 De la Peña Martínez, F. (2003). Antropología del presente y globalización. Boletín De Antropología Americana, (39), 175-183. 
La globalización influye de manera diferente en cada ciencia, generando diversos enfoques, estudios, y fenómenos. "No creo que se pueda decir que la globalización es únicamente o incluso básicamente un fenómeno económico, ni creo que se pueda decir que sus fuerzas impulsoras sean única o básicamente económicas. La globalización es política, cultural y social”. ${ }^{12}$ (Giddens, 2001, 62).

La relación del Derecho con la globalización está ligada a la sociedad que se encuentra bajo sus efectos y en constante cambio. Para interactuar en este proceso de globalización es necesario anexar el Derecho a la sociedad globalizada actual, la jurisprudencia de conceptos ya no es suficiente para el estudio legal del siglo XXI.

Una de las cuestiones que debemos considerar, es respecto a la aplicación de fronteras en el Derecho. Actualmente una de las características más representativas de la ley es la territorialidad, sin embargo, con la globalización las fronteras comerciales y económicas están desapareciendo y se agudiza la necesidad de contar con regulaciones internacionales que protejan las transacciones que se realizan fuera de los ordenamientos jurídicos nacionales.

El Derecho Internacional Público y Privado es el más cercano a la atención de estos conflictos, sin embargo, la evolución de la tecnología y el desarrollo de la sociedad le exige cada vez más. Los cambios ocurren con mayor velocidad y la norma sigue estática.

La globalización presenta problemáticas como la confidencialidad y manejo adecuado de la información personal y empresarial, el almacenamiento y uso de datos, la eficacia de las normas frente a la aparición de "softwares" o sistemas operativos que no están contemplados en la legislación, etc.

\section{a. La interdisciplinariedad y el Derecho}

Una de las respuestas que pueden presentarse a los abogados a manera de solución de las problemáticas que trae la globalización, es el aprendizaje interdisciplinario y transversal.

12 Giddens, A. (2001). El gran debate sobre la globalización. Pasajes, (7), 62-73. 
Los abogados en cualquier posición que se encuentren, si quieren participar de manera activa en los procesos derivados de la globalización, deben conocer de tecnología, computación, economía, finanzas, etc.

Sin embargo, ante la presencia de una enseñanza y ejercicio legal abstracto, basado en conceptos y bajo un enfoque tradicional positivista como se señaló anteriormente, se presenta una resistencia al trabajo interdisciplinario. Cuando se habla de interdisciplinariedad entre ciencias sociales "en general se excluye al Derecho, cuyo carácter normativo le da un estatus distinto”. ${ }^{33}$ (Puga, 2009, 106).

Las distintas ramas del Derecho abarcan en general los diversos comportamientos humanos. "A pesar de especialidades clásicas, el Derecho no pierde de vista los avances sociales, tecnológicos, culturales y científicos, lo que implica que se ocupe de las innovaciones que se generan en estos campos y que cada día se especialice más o surjan nuevas ramas, acordes con dichos avances del saber humano". ${ }^{14}$ (Lara, 2007, 8) La ciencia jurídica se interrelaciona con aquellas disciplinas que reflejen la conducta humana y se encuentren vinculadas al ámbito social: economía, historia, psicología, sociología, medicina, ingeniería, contaduría, etc. "Cada vez es más evidente que, más que nunca, estamos obligados a un aprendizaje permanente, para no quedar postergados en la sociedad del conocimiento. Uno tiene que adiestrarse intelectualmente todos los días para poder ser competitivo". ${ }^{15}$ (Puig, 2008, 209)

\section{INTERDISCIPLINARIEDAD EN LA ADMINISTRACIÓN DE JUSTICIA}

Como se mencionó, la administración de justicia es una parte fundamental del sistema jurídico dentro de una sociedad. A través de ella se intenta dar solución a los conflictos, mediante la interpretación y aplicación de los criterios y las pautas contenidas en las leyes y demás disposiciones generales. El juez quien es el depositario de la confianza del pueblo es quien dicta la sentencia en ejercicio de la función ju-

13 Puga, C. (2009). Ciencias sociales, un nuevo momento. Revista Mexicana de Sociología, 70, 106-107.

14 Lara, C. (2007). El Derecho, verdadera ciencia interdisciplinaria. Revista Jurídica UBA, 8-10.

15 Puig, V. (2008). Globalización, tecnología y libertad. Cuadernos de Pensamiento Político, (19), 209-224. 
risdiccional -potestad pública de juzgar y ejecutar lo juzgado-, tiene una función y competencia específica que le otorga la Constitución y la ley; por lo cual es llamado a resolver los diferentes problemas y conflictos que se presentan en la sociedad producto de las diversas interrelaciones sociales, para lo cual debe otorgar a cada uno de los sujetos procesales lo que les corresponda en Derecho.

En esta línea, el artículo 76 de la Constitución de la República del Ecuador dispone: "En todo proceso en el que se determinen derechos y obligaciones de cualquier orden, se asegurará el derecho al debido proceso que incluirá las siguientes garantías básicas: 1 . Corresponde a toda autoridad administrativa o judicial, garantizar el cumplimiento de las normas y los derechos de las partes" ${ }^{16}$

El papel del juez debe ser imparcial, intachable, justo. Para cumplir con todos esos requisitos, debe contar con un vasto conocimiento no solo de la legislación, sino de todas las ramas académicas vinculadas con el desarrollo de la sociedad. El juez diariamente en su ejercicio profesional, y personal debe absorber, conocer, estudiar, fundamentar y resolver conflictos y temas muy diversos en los que se involucran los diversos campos de la ciencia jurídica.

Por ejemplo, ¿̇cómo podría un juez resolver un litigio sobre telecomunicaciones, sin entender los lineamientos básicos del funcionamiento de esta industria?

Es difícil pensar que una resolución sea justa si proviene de un juez que no conoce nada del objeto de la litis, y únicamente basa su decisión en los tecnicismos legales.

Las normas se encuentran en constante cambio; cada mañana pueden entrar en vigencia un sinnúmero de normas nuevas y diferentes. El juez y el abogado que ejercen la profesión deben tener un saber extenso acerca de las diversas ciencias con las que se vea relacionado el conflicto del cual debe dictar sentencia en el caso del juez.

Debemos prepararnos para aplicar el derecho ante escenarios de vanguardia. Únicamente a manera de ejemplo, si un usuario interpone una demanda contra Facebook, no es suficiente que el juez que conocerá el

16 Artículo N 76.1. Constitución de la República del Ecuador, Montecristi, Ecuador 20 de octubre de 2008 . 
caso, maneje la norma técnica legal, sino que conozca cómo opera Facebook, el alcance de sus funciones comerciales, con la finalidad de conocer la realidad del conflicto, y por lo tanto, contar con herramientas más adecuadas para la resolución de la pretensión del usuario.

La sentencia se ve influenciada por el razonamiento jurídico y el conocimiento del juez "es sabido que la aplicación del Derecho es algo universal, incluso las tribus de estructura social más simple tienen un sistema por medio del cual imparten justicia, pero también es sabido que su aplicación varía de acuerdo con el sistema, corriente, etc. Estas variaciones provocan que, al momento de resolver un problema, se razone y decida de distinta manera." ${ }^{17}$ (Lionetti, 2017, 3). Es fundamental que el razonamiento del juez sea antecedido por una serie de conocimientos, legales, sociales, económicos, políticos, culturales, ambientales etc.

Como establece la Constitución de la República del Ecuador en el artículo 76.7.1 "Las resoluciones de los poderes públicos deberán ser motivadas. No habrá motivación si en la resolución no se enuncian las normas o principios jurídicos en que se funda y no se explica la pertinencia de su aplicación a los antecedentes de hecho. Los actos administrativos, resoluciones o fallos que no se encuentren debidamente motivados se considerarán nulos. Las servidoras o servidores responsables serán sancionados". ${ }^{18}$ Se puede concluir que los jueces tienen la obligación de motivar sus sentencias si esto no ocurre la consecuencia será la nulidad de los mismos. Es fundamental que la motivación se encuentre bajo la influencia de un razonamiento jurídico interdisciplinario, más aún cuando se exige que la motivación sea la explicación del porqué el juez aplicó una determinada norma frente a la situación fáctica que se le puso a su conocimiento.

Como expresa Villarejo: "Se debe tener en cuenta que la justicia no consiste solo en dar a cada uno lo suyo sino también en preguntarse constantemente qué es lo que a cada uno se debe dar como suyo.

Este concepto de la justicia que problematiza constantemente el Derecho es incompatible con una interpretación estática de la norma. En este sentido, la justicia es algo así como una invitación constante a la

17 Lionetti, J. (2017). Razonamiento jurídico y toma de decisión. Revista de Filosofia, Política y Derecho, 3, 3-22.

18 Artículo N 76.7.1 Constitución de la República del Ecuador, Montecristi, Ecuador 20 de octubre de 2008 . 
innovación". ${ }^{19} \mathrm{El}$ jurista no debe ser experto en todo, pero si debe dominar conocimientos básicos de las distintas ciencias en las cuales se encuentre el conflicto, puesto que un juez no puede desinteresarse de la realidad, la misma que se encuentra regida por la interdisciplinariedad, con el pretexto que su función es únicamente jurídica.

"El juez o magistrado es aquel tercero imparcial que aplicando las reglas de la sana crítica, reglas que le permitirán apreciar las pruebas objetivamente para descubrir la verdad sobre la falsedad y dictaminará sobre el asunto controvertido sometido a su conocimiento, que se reflejará en la sentencia que es el acto judicial supremo, pues allí el juez ejercerá su jurisdicción y competencia que le otorga la ley y la Constitución de la República, o lo que es lo mismo, dirá el derecho aplicable a conflicto" ${ }^{20}$ (Benavides, 2014, 1). Para resolver los distintos conflictos de una manera justa y eficiente es fundamental el trabajo interdisciplinario del Derecho y las demás ciencias sociales.

Es necesario un cambio en el modelo de enseñanza del Derecho, "la defensa del pensamiento único, de una sola vía de conocimiento y de una sola capacidad interpretativa ya demuestra por sí misma que tal elección se fundamenta en la incapacidad de contener el miedo de aceptar la realidad plural de acceso a la comprensión e interpretación de las cosas". ${ }^{21}$ (Vinyamata, 2000, 31).

Por esta razón es necesario promover más argumentación jurídica contextualizada en la investigación e información desde otras disciplinas; "Esta invitación parte de la observación que en muchas de las aulas en las que se enseña Derecho en proyectos que se conciben en oposición al modelo de educación que se ha impartido tradicionalmente, casi no existe siquiera una relación incómoda con la producción de otras disciplinas" (Bergallo, 2015, 3). ${ }^{22}$

19 Marsal, S., Villarejo, J., Marco, A., y Figueroa, M. (2001). Vida de juez. El Ciervo, $50(601), 24-28$

20 Benavides, M. (2014). El rol del juez en la administración de justicia. Revista de Derecho Ecuador, 1-2.

21 Vinyamata, E. (2000). La Resolución de Conflictos, una nueva disciplina. El Ciervo, 48(578), 31-33.

22 Bergallo, P. (2015). El Derecho y las ciencias sociales: ni siquiera una relación incomoda. Universidad de Palermo. 2-14. 


\section{a. El cambio en la educación legal}

Como ya se mencionó, la educación legal que se imparte en las facultades de Jurisprudencia, especialmente en Latinoamérica, se ha basado en un enfoque tradicional positivista de un derecho de conceptos, y aplicación y uso de la coacción, dejando de lado la formación interdisciplinaria de los futuros abogados y jueces.

"En caso de duda, hay que optar por la libertad. Nos encontramos en una sociedad con una fuerte tentación de imponer un pensamiento único". ${ }^{23}$ (Ramos, 2009, 172). Es necesario cambiar el sistema educativo, establecer como política educativa que el Derecho debe estar interrelacionado con las diferentes ciencias sociales "al hablar de ciencias sociales nos referimos a un conjunto de disciplinas que, a partir del interés explicito por diferentes aspectos de la vida colectiva, han formulado teorías generales y planteamientos analíticos” ${ }^{24}$ (Puga, 2009, 105).

La educación cimienta las bases del futuro desarrollo profesional de los abogados y jueces, "el sistema educativo de un país es el espejo de su situación social” ${ }_{25}$ (Gómez, 1969, 1).

Medina afirma que: "la educación entraña modificaciones profundas y beneficiosas para el individuo, gracias a las cuales asume el papel de persona, ciudadano, profesional etc. Contribuye a la socialización en los valores de la sociedad al tiempo que ayuda a la emancipación y a la mejora de la calidad de vida, proporciona al individuo aptitudes y cualificaciones profesionales que le permitirán concurrir, en condiciones más favorables que las de aquel que tiene menos años de educación, al mercado de trabajo, adquiriendo, en consecuencia, un estatus de importancia proporcional a los títulos conseguidos” ${ }^{26}$ (Medina, 2013, 7)

Por lo tanto, se puede afirmar que la educación es la base del desarrollo de la sociedad y el pilar en la formación de profesionales. "No existe hoy en nuestro medio, un solo abogado que pueda defender un caso

23 Ramos, J. (2009). Libertad de educación y respeto a la diferencia. Cuadernos de Pensamiento Político, (24), 161-173

24 Puga, C. (2009). Ciencias sociales. Un nuevo momento / Social Sciences. A New Moment. Revista Mexicana de Sociología, 71, 105-131.

25 Gomes, L. (1969). La educación y el futuro. El Ciervo, 18(185), 1-1.

26 Medina, E. (2013). Universidad y mercado de trabajo. Revista Española de Investigaciones Sociológicas, 5, 7-46. 
apoyándose en un artículo del sistema de la codificación. En los escritos judiciales encontramos cada día más referencias a las teorías de los jueces. Estas teorías, tomadas de fallos anteriores, o de votos emitidos personalmente, han venido a ocupar en la larga medida, el lugar que antes correspondía a los grandes comentaristas de ley” ${ }^{27}$ (Cobiella, 2014, 6).

En el caso del Derecho con la presencia de una educación legal poco práctica y abstracta, se presenta una resistencia y oposición a la interdisciplinariedad entre ciencias. Como resultado, se crearán abogados con menor capacidad de reacción frente a los retos que el mundo globalizado implica.

Se requiere que los estudiantes de Derecho conozcan la realidad social, se acerquen a las empresas y participen no solo desde el ámbito legal, sino que se involucren en los procesos productivos, en la creación de los productos o servicios, con la finalidad de entender el por qué se aplica cada norma a cada una de las realidades.

Los jueces deben conocer lo que la sociedad está haciendo. Se requiere de manera inminente la coparticipación educativa de la academia, el Estado y la sociedad civil. No pueden seguirse considerando entes aislados que confluyen cuando cada uno tiene los criterios formados. Deben nacer juntos, con el planteamiento de metas comunes. Solo esto conseguirá que la política educativa de los abogados se integre a los requerimientos reales de la sociedad.

\section{b. Constitución de la República del Ecuador del año 2008, un ejemplo de adaptabilidad del Derecho.}

La Constitución ecuatoriana aprobada el 28 de septiembre del 2008 , puede ser considerada un ejemplo de vanguardia legal respecto a temáticas sociales actualizadas. La carta magna ubica al Ecuador en la lista de países pioneros en el ejercicio del constitucionalismo ambiental que se ha desarrollado en una serie de países latinoamericanos. Y es un claro ejemplo del resultado del trabajo interdisciplinario en el ámbito jurídico.

27 Cobiella, M. y Mirow, M. (2014). Educación Legal en los Estados Unidos I: Facultades de Derecho y el Juris Doctor. The University of Miami Inter-American Law Review, 46(1), 1-38. 
"El objetivo último de toda Constitución es lograr un mejor gobierno. Se entiende por tal, la acción de dirigir, conducir a los hombres, las cosas y las relaciones que surgen entre uno y otro, o entre sí, respectivamente. Dentro de estos elementos se encuentra lógicamente la naturaleza y el medio ambiente" ${ }^{28}$ (Macías, 2012, 2).

En nuestra norma suprema, la naturaleza es considerada como sujeto de derechos, generando cambio y marcando un hito en el derecho ambiental. La Constitución ecuatoriana en el artículo 71 dispone que: "la naturaleza o Pacha Mama, donde se reproduce y realiza la vida, tiene derecho a que se respete integralmente su existencia y el mantenimiento y regeneración de sus ciclos vitales, estructura, funciones y procesos evolutivos." ${ }^{29}$

Además, el artículo 14 del mismo cuerpo legal indica: "Se reconoce el derecho de la población a vivir en un ambiente sano y ecológicamente equilibrado, que garantice la sostenibilidad y el buen vivir, sumak kawsay. Se declara de interés público la preservación del ambiente, la conservación de los ecosistemas, la biodiversidad y la integridad del patrimonio genético del país, la prevención del daño ambiental y la recuperación de los espacios naturales degradados" (Constitución de la República del Ecuador, 2008). ${ }^{30}$

Se puede apreciar que para el legislativo ecuatoriano, la naturaleza no solo es un instrumento para lograr el bien común en la sociedad; al dar paso al reconocimiento de los derechos de la naturaleza, se asegura el bienestar de la sociedad y se la considera como un sujeto de derechos sui géneris, lo cual hace dos décadas era impensable.

A base de la consideración de los derechos de la naturaleza, la Constitución ha incluido obligaciones para todos los demás actores de la sociedad. A manera de ejemplo, el artículo 15 señala: "El Estado promoverá, en el sector público y privado, el uso de tecnologías ambientalmente limpias y de energías alternativas no contaminantes y de bajo impacto. La soberanía energética no se alcanzará en detri-

28 Macías, L. (2012). El constitucionalismo ambiental en la nueva Constitución de Ecuador. Un reto a la tradición constitucional. Revista jurídica Iurisdictio, 14, 2-3.

29 Artículo $N^{\circ}$ 71. Constitución de la República del Ecuador, Montecristi, Ecuador 20 de octubre de 2008.

30 Artículo $\mathrm{N}^{\circ}$ 14. Constitución de la República del Ecuador, Montecristi, Ecuador 20 de octubre de 2008 . 
mento de la soberanía alimentaria, ni afectará el derecho al agua. Se prohíbe el desarrollo, producción, tenencia, comercialización, importación, transporte, almacenamiento y uso de armas químicas, biológicas y nucleares, de contaminantes orgánicos persistentes altamente tóxicos, agroquímicos internacionalmente prohibidos, y las tecnologías y agentes biológicos experimentales nocivos y organismos genéticamente modificados perjudiciales para la salud humana o que atenten contra la soberanía alimentaria o los ecosistemas, así como la introducción de residuos nucleares y desechos tóxicos al territorio nacional". ${ }^{31}$ Se establece la responsabilidad y el compromiso estatal con el medio ambiente.

En el artículo 414 del mismo cuerpo legal el Estado asume medidas preventivas contra el cambio climático y la degradación del medio ambiente, para la preservación del ecosistema y la convivencia en un entorno medio ambiental óptimo. "El Estado adoptará medidas adecuadas y transversales para la mitigación del cambio climático, mediante la limitación de las emisiones de gases de efecto invernadero, de la deforestación y de la contaminación atmosférica; tomará medidas para la conservación de los bosques y la vegetación, y protegerá a la población en riesgo". ${ }^{32}$

Según Brunicelli: "puede afirmarse que el futuro de la materia (el medio ambiente) se orientará hacía la sistematización de la normativa interna e internacional del derecho ambiental, a la creación de los correspondientes órganos de tutela, y a la definición de los procedimientos que hagan posible y faciliten la exigibilidad del respeto a tales derechos". ${ }^{33}$

La finalidad de hacer referencia a esta Constitución es demostrar la importancia de implementar una visión holística, interdisciplinaria e integral que permita generar soluciones a los crecientes problemas sociales que se han presentado en el siglo XXI. En el área del derecho ambiental, Ecuador consagra principios y derechos novedosos referentes a la naturaleza y la protección del ambiente generando nuevas responsabilidades tanto a escala nacional como internacional. Esto no

31 Artículo $\mathrm{N}^{\circ}$ 15. Constitución de la República del Ecuador, Montecristi, Ecuador 20 de octubre de 2008.

32 Artículo $\mathrm{N}^{\circ} 414$. Constitución de la República del Ecuador, Montecristi, Ecuador 20 de octubre de 2008.

33 Brunicelli, M. (2012). El derecho al ambiente sano como derecho humano fundamental. Revista Fundación De Derechos Humanos, 8, 4. 
habría sido posible sin el trabajo con una ciencia diferente; en este caso las ciencias ambientales.

Este caso únicamente presenta un ejemplo aislado, porque el presente documento no es suficiente para señalar un sinnúmero de ramas legales que actualmente requieren la cooperación de otros profesionales, como es el caso del Derecho de competencia, que al regular el poder de mercado y participación de las empresas en los distintos ámbitos comerciales, necesita de economistas que conozcan el comportamiento del mercado donde se desenvuelven las empresas.

\section{CONCLUSIONES}

Al considerar a la educación como base del desarrollo de la sociedad, es necesario cambiar la enseñanza del Derecho de conceptos basado en un enfoque tradicional exclusivamente positivista que genera que la educación legal sea limitante y exigua, consecuentemente el estudiante quien será en el futuro abogado o juez no trascenderá profesionalmente en el ejercicio de su carrera, dejando que su rol profesional sea relegado únicamente al conflicto. "Cuanto mayor es el bagaje cultural de un futuro profesional, mayor será su desempeño" (Kuns, 2016, 1). ${ }^{34}$ Al no admitir la interdisciplinariedad entre el Derecho y las diversas ciencias sociales, se produce un retroceso en la relación Derecho y Globalización.

El Derecho impregna, dirige y regula, los actos humanos. En el siglo XXI que se encuentra bajo los efectos de la globalización y la tecnología; enfocarse y abstraerse en la idea exclusiva de un Derecho positivo, basado en conceptos que no incorporen la participación y el trabajo conjunto entre ciencias es absurda y muy poco efectiva. La sociedad está en constante cambio, por lo tanto, se generan varios problemas que están relacionados con factores, y sucesos que se encuentran fuera de la ciencia jurídica.

El Juez y el abogado no pueden desatender la realidad, deben dominar ciertas ideas y conceptos que se encuentren fuera del Derecho. En el caso del juez, su función es administrar justicia, por lo tanto, emitir una sentencia frente a un conflicto sin conocimiento del objeto que

34 Kuns, A. (2016). Comentarios al ensayo el derecho y las humanidades: una relación incómoda. Revista Jurídica Universidad de Palermo, (1),229-234. 
generó la litis, permitirá que la sentencia no corresponda a la realidad de los hechos. La sentencia está influenciada por el razonamiento jurídico y el conocimiento del juez; es fundamental que el conocimiento del juez sea vasto y diverso en el origen del caso que está resolviendo, que trascienda más allá del ámbito legal; esto generara que la administración de justicia sea más eficiente y justa.

La Constitución ecuatoriana del año 2008 marca un hito en el constitucionalismo latinoamericano en el ámbito de la naturaleza y preservación del medio ambiente y es un claro ejemplo de los resultados de un trabajo interdisciplinario entre dos ciencias, el Derecho y las ciencias naturales, sin embargo, esto no es suficiente, porque si tenemos una Constitución desconectada del resto del ordenamiento jurídico y de la aplicación de la justicia, no será efectiva.

\section{REFERENCIAS BIBLIOGRÁFICAS}

Alegria, H. (2017). Derecho y Globalización. Revista Jurídica UBA. 187. Recuperado de: http://www.derecho.uba.ar/publicaciones/pensar-en-derecho/revistas/0/globalizacion-y-derecho.pdf

Ansolabehere, K. (2008). Legalistas, legalistas moderados y garantistas moderados: Ideología legal de maestros, jueces, abogados, ministerios públicos y diputados / Legalists, Moderate Legalists and Moderate Guarantists: Legal Ideology of Teachers, Judges, Lawyers, Attorney Generals and Representatives. Revista Mexicana De Sociología, 70(2), 331359. Recuperado de: http://puceftp.puce.edu.ec:2053/stable/20454336

Beade, G.A. (2015). Los problemas del unitarismo del derecho. Revista Jurídica Universidad de Palermo,221-222. Recuperado de: http:// www.palermo.edu/derecho/revista_juridica/pub-14/Revista_Juridica_Ano14-N2_09.pdf

Benavides, M. (2014). El rol del juez en la administración de justicia. Revista de Derecho Ecuador, 1-2. Retrieved from http://www.derechoecuador.com/articulos/detalle/archive/doctrinas/funcionjudicial/2014/02/12/el-rol-del-juez-en-la-administracion-de-justicia- 
Bergallo, P. (2015). El Derecho y las ciencias sociales: ni siquiera una relación incomoda. Universidad de Palermo. 2-14. Recuperado de: http:// www.palermo.edu/derecho/revista_juridica/09Jurica11.pdf

Brunicelli, M. (2012). El derecho al ambiente sano como derecho humano fundamental. Revista Fundación de Derechos Humanos, 8, 4. Recuperado de: http://www.cladh.org/uncategorized/el-derecho-ambiental-en-el-desarrollo-humano/

Cobiella, M. y Mirow, M. (2014). Educación Legal en los Estados Unidos I: Facultades de Derecho y el Juris Doctor. The University of Miami Inter-American Law Review, 46(1), 1-38. Recuperado de: http://puceftp.puce.edu.ec:2053/stable/24375801

De la Peña Martínez, F. (2003). Antropología del presente y globalización. Boletín de Antropología Americana, (39), 175-183. Recuperado de: http://puceftp.puce.edu.ec:2053/stable/40978226

Giddens, A. (2001). El gran debate sobre la globalización. Pasajes, (7), 62-73. Recuperado de: http://puceftp.puce.edu.ec:2053/stable/ pdf/10.2307/23074573.pdf?refreqid=search\%3Aadd0bbd93c4036c$74 \mathrm{fb} 2 \mathrm{be} 39 \mathrm{e} 0 \mathrm{bc} 74 \mathrm{~d} 8$

Gomes, L. (1969). La educación y el futuro. El Ciervo, 18(185), 1-1. Recuperado de: http://puceftp.puce.edu.ec:2053/stable/40803689

Gomis, L. (2002). No hay justicia sin jueces. El Ciervo 39(475/476), 3-3. Recuperado de: http://puceftp.puce.edu.ec:2053/stable/40819792

Hernández, R. (2017). La crisis del positivismo jurídico. Revista jurídica Ámbito Jurídico, (2), 1-11. Recuperado de: http://www.ambito-juridico.com.br/site/?n_link=revista_artigos_leitura\&artigo_id=15192

Kuns, A. (2016). Comentarios al ensayo el derecho y las humanidades: una relación incomoda. Revista Jurídica Universidad de Palermo, (1),229-234. Recuperado de: http://www.palermo.edu/derecho/revista_juridica/09Jurica09.pdf

Lionetti, J. (2017). Razonamiento jurídico y toma de decisión. Revista de Filosofia, Política y Derecho, 3, 3-22. Recuperado de: http://universitas.idhbc.es/n03/03-02_lionetti.pdf 
Macías, L. (2012). El constitucionalismo ambiental en la nueva Constitución de Ecuador. Un reto a la tradición constitucional. Revista jurídica Iurisdictio, 14, 2-3. Recuperado de: http://www.usfq.edu.ec/ publicaciones/iurisDictio/archivo_de_contenidos/Documents/IurisDictio_14/iurisdictio_014_008.pdf

Marsal, S., Villarejo, J., Marco, A. y Figuera, M. (2001). Vida de juez. El Ciervo, 50(601), 24-28. Recuperado de: http://puceftp.puce.edu. ec:2053/stable/40829625

Medina, E. (2013). Universidad y mercado de trabajo. Revista Española de Investigaciones Sociológicas, 5, 7-46.

Muñoz, C. (2013). El oficio de ser Juez. Revista de Derecho UNAM, 5, 2-8. Recuperado de http://www.revistajuridicaUNAM/files/ELJUEZ-DEL-SIGLOXXII.pdf

Puga, C. (2009). Ciencias sociales, un nuevo momento. Revista Mexicana de Sociología, 70, 106-107. Recuperado de: http://puceftp.puce. edu.ec:2053/stable/25677024

Puig, V. (2008). Globalización, tecnología y libertad. Cuadernos de Pensamiento Político, (19), 209-224. Recuperado de: http://puceftp.puce. edu.ec:2053/stable/25597148

Ramos, J. (2009). Libertad de educación y respeto a la diferencia. Cuadernos de Pensamiento Político, (24), 161-173. Recuperado de: http:// puceftp.puce.edu.ec:2053/stable/25597264

Tiznado, J. (2011). Tolerancia, autonomía e inmoralidades "inofensivas" o "sin víctimas". Crítica: Revista hispanoamericana de filosofía, 43(128), 81-86. Recuperado de: http://puceftp.puce.edu.ec:2053/sta$\mathrm{ble} / \mathrm{pdf} / 23041416$.pdf?refreqid=search:154a1f0047f5662e $5878 \mathrm{db}-$ $2 \mathrm{~d} 375 \mathrm{e} 54 \mathrm{cb}$

Vinyamata, E. (2000). La Resolución de Conflictos, una nueva disciplina. El Ciervo, 48(578), 31-33. Recuperado de: http://puceftp.puce. edu.ec:2053/stable/40822969 


\section{Base Legal}

Artículo N 14 Constitución de la República del Ecuador, Montecristi, Ecuador 20 de octubre de 2008.

Artículo N 15 Constitución de la República del Ecuador, Montecristi, Ecuador 20 de octubre de 2008.

Artículo No 71. Constitución de la República del Ecuador, Montecristi, Ecuador 20 de octubre de 2008.

Artículo No 76.7.1. Constitución de la República del Ecuador, Montecristi, Ecuador 20 de octubre de 2008.

Artículo $\mathrm{N}^{\circ}$ 414. Constitución de la República del Ecuador, Montecristi, Ecuador 20 de octubre de 2008.

Recibido: 22/01/2017

Aceptado: 27/05/2017

Gabriela Estefanía Coronel Loayza: Investigadora Jurídica Estudio Vaca \& Asociados

Mgtr. Jessahé Carla Navarrete Villalba: Docente titular PUCE (Facultad de Jurisprudencia)

Correo electrónico: gaby.coronel8@hotmail.com

Correo electrónico: cjnavarrete@puce.edu.ec 